Marshall University

Marshall Digital Scholar

Biological Sciences Faculty Research

Biological Sciences

2009

\title{
A plesiosaur containing an ichthyosaur embryo as stomach contents from the Sundance Formation of the Bighorn Basin, Wyoming
}

F. Robin O'Keefe

Marshall University, okeefef@marshall.edu

Hallie P. Street

Marshall University

Jean Pierre Cavigelli

John J. Socha

R. Dennis O'Keefe

Follow this and additional works at: http://mds.marshall.edu/bio_sciences_faculty

Part of the Animal Sciences Commons, and the Ecology and Evolutionary Biology Commons

\section{Recommended Citation}

O'Keefe, F. R., Street, H. P., Cavigelli, J. P., Socha, J. J., \& O'Keefe, R. D. (2009). A plesiosaur containing an ichthyosaur embryo as stomach contents from the Sundance Formation of the Bighorn Basin, Wyoming. Journal of Vertebrate Paleontology, 29(4), 1306-1310. 


\title{
A PLESIOSAUR CONTAINING AN ICHTHYOSAUR EMBRYO AS STOMACH CONTENTS FROM THE SUNDANCE FORMATION OF THE BIGHORN BASIN, WYOMING
}

\author{
F. ROBIN O'KEEFE \\ HALLIE P. STREET \\ JEAN PIERRE CAVIGELLI \\ JOHN J. SOCHA \\ R. DENNIS O'KEEFE
}

Herein we report the discovery of an ichthyosaur embryo from the Upper Member of the Sundance Formation (Oxfordian) of the Bighorn Basin, Wyoming. The specimen is the first known ichthyosaur embryo from the Upper Jurassic, and is the first Jurassic ichthyosaur embryo from North America. The embryo was discovered in close association with the abdomen of an articulated partial plesiosaur skeleton, and several lines of evidence support the interpretation of the embryo as plesiosaur stomach contents. The small size and extremely poor ossification of the embryo indicate that the animal was probably not a neonate. Although the taxonomic affinities of the fossil are unknown, the large ichthyosaurian (sensu stricto) Opthalmosaurus natans is the only known ichthyosaur from the Sundance Formation, and the embryo may belong to that taxon.

The ichthyosaurs and plesiosaurs of the Sundance Formation of Wyoming (Oxfordian) have been known for over 100 years, having been first mentioned by Marsh $(1891,1893,1895)$. The single currently recognized ichthyosaur taxon from the formation, Ophthalmosaurus natans, was described in a monograph by Gilmore (1906), but subsequently received little attention until recently (Massare and Young, 2004; Massare et al., 2006). Plesiosaurs are also known from the formation, comprising the large pliosaur taxon Megalneusaurus rex (Knight, 1898; Wahl et al., 2007) and the cryptocleidoid taxa Pantosaurus striatus (O’Keefe and Wahl, 2003a) and Tatenectes laramiensis (O’Keefe and Wahl 2003b; Mehl, 1912). These plesiosaur taxa have also received little attention in the scientific literature, despite their phylogenetic and biogeographic relevance to Jurassic plesiosaur evolution, and the context they may provide for the diverse and well-known plesiosaur fauna of the nearly coeval Oxford Clay of the United Kingdom (Andrews, 1910, 1913). In an effort to increase knowledge of this important fauna, the Sundance Plesiosaur Project has performed extensive fieldwork in the Upper Member of the Sundance Formation. Here we report on one discovery from this field program, a partial skeleton referable to Pantosaurus striatus. The skeleton is remarkable in preserving a gastric mass containing the partially digested remains of an embryonic ichthyosaur, and is the first evidence of the consumption of ichthyosaurs by plesiosaurs.

Institutional Abbreviation—USNM, Smithsonian Institution, Washington, D.C. USA. 


\section{MATERIAL AND DESCRIPTION}

The fossils described here were discovered in an extensive outcrop of the Upper Member of the Sundance Formation, north of the town of Greybull, Wyoming. This unit is composed primarily of glauconitic grey-green shale, interspersed with irregular fine-grained sandstone beds (O’Keefe and Street, 2009). Invertebrate fossils are abundant, with Pachyteuthis densus and Ostrea sp. being the most common. The Sundance Upper Member is the depositional record of the final transgressiveregressive cycle of the Sundance Seaway (Wahl, 2006; O'Keefe and Street, 2009), and is firmly dated as Oxfordian using ammonite biostratigraphy (Kvale et al., 2001). Initial discovery of an articulated, large partial skeleton occurred in 2004; the fossil was collected and subsequently prepared (by J.P.C.) in 2005.

The plesiosaur skeleton comprises a complete pelvis, 15 vertebrae ( 4 dorsals, 3 sacrals, and eight caudals), and numerous ribs and gastralia (Fig. 1A). The vertebral column was articulated when found, while the pelvic elements were in articulation except at the midline. The ribs and gastralia were disorganized and densely interfingered with the other elements. Interspersed within this mass were several small, ring-shaped bones and small polished stones, while just beneath the ribs and gastralia was a mass of sand and grit containing bone fragments, fish scales, a series of ring-shaped bones, and other small elements (Fig. 1B, C). A firm taxonomic assignment for the plesiosaur skeleton is complicated by the uninformative nature of the Pantosaurus striatus holotype, which is both incomplete and juvenile (O'Keefe and Wahl, 2003a). However, a preliminary assessment indicates that the skeleton is referable to Pantosaurus. Features of the pelvic girdle establish that the skeleton is a cryptocleidid, and similar to Muraenosaurs from the Oxford Clay (Andrews, 1910; Brown, 1981); the close similarity between Muraenosaurus and Pantosaurus has been remarked upon by previous authors (O’Keefe and Wahl, 2003a, and references therein). The skeleton is certainly not a true pliosaur (i.e., Megalneusaurus), and differs markedly from Tatenectes in overall body size, rib and gastralium morphology, and details of the dorsal and sacral vertebrae.

Identification of the ring-shaped bones as ichthyosaur vertebrae was not immediate; ichthyosaur embryos of this ontogenetic stage are generally found within a gravid female. There are 13 complete rings and fragments of 4 more, and five of the rings are articulated (Fig. 1C), while a preliminary CT scan revealed at least one more unprepared vertebra within the matrix block. All of the rings are 12-15 mm in diameter, and only 2-3 mm thick; most are relatively featureless, although several bear faint processes for articulations with other bones (Fig. 2C). A survey of the literature revealed a strong similarity between the ring bones and very poorly ossified ichthyosaur vertebrae discovered within the body cavity of the Cretaceous ichthyosaur Maiaspondylus by Maxwell and Caldwell (2003; 2005), bearing a similar, widely open notochordal canal. Adult ichthyosaur vertebrae are short antero-posteriorly and deeply amphiceolus, but the notochordal canal is closed (Fig. 2B). The ring bones are also an order of magnitude smaller than a typical Sundance adult ichthyosaur centrum. 

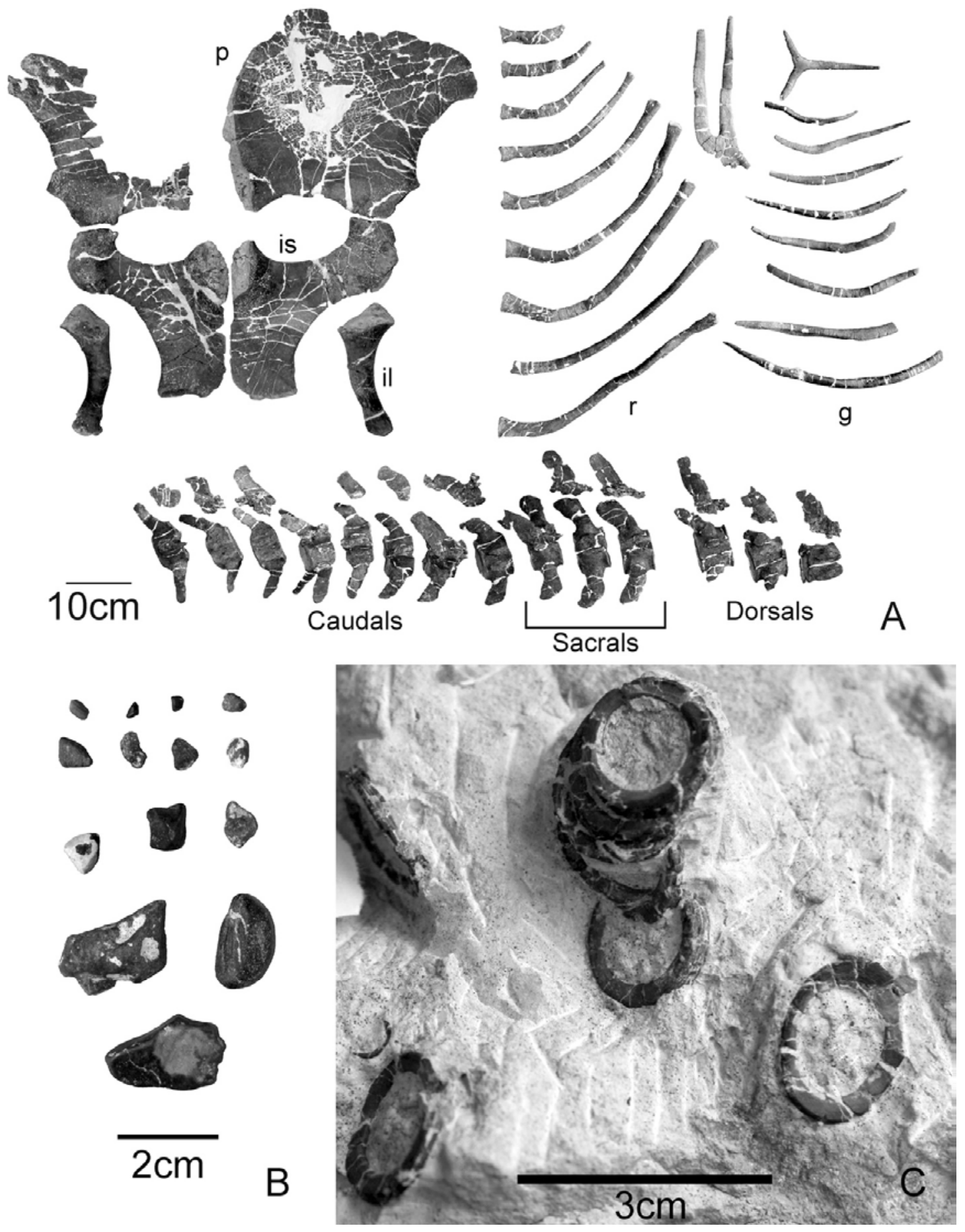

FIGURE 1. A, partial plesiosaur skeleton (c.f. Pantosaurus striatus) from the Sundance Form-ation, Wyoming (USNM 536965). Girdle elements are displayed in dorsal view. Fourteen vertebrae are illustrated in dorsal view; the 15 th vertebra is poorly preserved and not shown, and most of the neural arches are broken and disarticulated. The illustrated ribs and gastralia are a representative subset of relatively complete elements. Abbreviations: g, gastralia; il, ilium; is, ischium; $p$, pubis; r, ribs. B, gastroliths found in association with ichthyosaur embryo. C, block of matrix containing sandsized grit and partially articulated embryonic ichthyosaur vertebrae. 
The case for interpretation of the ring bones as ichthyosaur vertebrae was confirmed by the discovery of a small cranial element amongst the vertebrae (Fig. 2A). This $7 \mathrm{~mm}$ element is a fragment of a tooth row from either the mandible or maxilla/premaxilla. The fragment contains the alveoli of at least four teeth, which are sub-millimeter in scale. No tooth crowns are present, but roots are preserved in the alveoli. The tooth roots clearly possess infolded dentine surrounded by cementum, a diagnostic condition of ichthyosaurs, and figured in the genus Ophthalmosaurus by Andrews (1910; however, for further discussion see below). A partial left scapula was also recovered. The dorso-lateral scapular blade is missing, and the medial portion is very poorly ossified, consisting of a sheath of periosteal bone surrounding a wedge-shaped matrix core that was presumably cartilaginous in life. The external surface of the scapula is also macerated and heavily fragmented. Taken together, the vertebral centra, identifiable scapula, and diagnostic tooth row confirm the assignment of the tiny skeleton to the Ichthyosauria. The majority of the vertebral centra noted above, including the articulated series, are enmeshed in a coherent mass of sand and grit whose lithology differs markedly from the surrounding shale. The mass also included a few gastroliths, only 3 of which were over $2 \mathrm{~cm}$ in diameter; there are several of about $1 \mathrm{~cm}$ in diameter, and many smaller stones whose size grades into that of the sub-millimeter sand and grit particles (Fig. 1B). The gastroliths differ in composition, with quartzite, feldspar, basalt, and olivine represented. The sand and grit fraction is heterogeneous, comprising basaltic and quartzitic sand, invertebrate shell fragments, vertebrate bone fragments, fish scales, and glauconite. The gastroliths have the pitted, polished surface typical of plesiosaur gastroliths (Thompson et al., 2007), but are relatively few in number, small, and angular.

\section{DISCUSSION AND CONCLUSIONS}

Several lines of evidence support the inference that the partial ichthyosaur skeleton figured here is preserved plesiosaur gut contents. The most obvious is the occurrence of the embryo within the abdominal skeleton of a plesiosaur. The extensive maceration of the scapular bone surface is suggestive of digestion by stomach acid. However, the strongest evidence is the gastric mass containing the articulated vertebrae. Lastly, gastroliths are a common occurrence in articulated plesiosaur skeletons (Thompson et al., 2007), as is their co-occurrence with food residue (Martill, 1992; Cicimurri and Everhart, 2001). The gastroliths are few and small by plesiosaurian standards, but comparable to those reported by Sato and Wu (2006) in a Cretaceous elasmosaur from Canada; also, the presence of a sand-sized fraction has been documented in both plesiosauroid and pliosauroid gastric masses (Andrews, 1913; Martill, 1992; Thompson et al., 2007), and is common in birds and other animals that ingest foreign bodies as an aid to digestion (Wings, 2007).

The fragmentary tooth row described here is attributed to the ichthyosaur embryo based on its distinctive, infolded dental morphology; however, the mode of tooth implantation in this element differs markedly from that observed in adult ichthyosaurs. The adult teeth of postTriassic ichthyosaurs are aulacodont, lacking discrete alveoli and instead occurring in a deep 'alveolar groove' enclosed by labial and lingual flanges on both the maxilla and dentary, to which the teeth are not ankylosed (terminology follows Mazin, 1983; adult morphological descriptions may be found in Gilmore, 1906; Andrews, 1910). Tooth implantation in the element in Figure 2 appears thecodont, a condition usually associated with basal archo- 
saurs among reptiles. This difference may be ontogenetic, or it may indicate that the tooth row is not ichthyosaurian; an almost complete lack of data on ichthyosaur dental ontogeny makes a determination difficult.

However, evidence from extant taxa implies that this difference may be ontogenetic. In his description of embryonic ontogeny in the (acrodont) lizard Lacerta vivipara, Rieppel (1992) documents that the maxilla and dentary ossify very early in ontogeny, before mineralization of the dental anlagen. These anlagen then begin mineralization within the bodies of the maxilla and mandible deep to the alveolar groove, and then grow into the groove before ankylosing to its labial and lingual margins. Breakdown of the interdental plate and fusion of adjacent teeth then occurs after this ankylosis (Zaher and Rieppel, 1999). Therefore, at an ontogenetic stage of acrodonty, the teeth begin to erupt from the surface of the dentary or maxilla prior to their ankylosis with the walls of the alveolar groove or fusion to one another. This sequence would create a transient, thecodont-like morphology. Rieppel (1992) does not describe the ossification of the labial and lingual walls of the alveolar grooves relative to the main bodies of the toothbearing elements, and a thecodont-like stage would only occur if the lingual and labial walls ossify relatively late. Obviously ichthyosaurs are not acrodont, making direct comparisons with lizard ontogeny suspect; however the pattern of dental development in extant lizards suggests that the observed morphology may be a plausible early stage in the early development of the ichthyosaurian dentition.

An estimate of the ontogenetic age of the ichthyosaur is difficult given the lack of gravid female fossils of Ophthalmosaurus, but the skeleton is probably not a neonate. The overall state of ossification is quite poor, comparable to that of prepartum ophthalmosaurian embryos described by Maxwell and Caldwell (2003), while the state of dental development described above is analogous to an early prepartum stage of modern lizard ontogeny. The only ichthyosaur for which a good pre-birth growth series is known is Stenopterygius (Bo“" ttcher, 1990); length at parturition in this genus is about $75 \mathrm{~cm}$ for a $200 \mathrm{~cm}$ adult, and the notochordal canal is closed or nearly so. A length estimate for the embryo described here is not possible, but the vertebral centra are tiny compared to those of adult Ophthalmosaurus (Fig. 2B; the adult centrum is about $10 \mathrm{~cm}$ in diameter, while the embryonic centrum is $1 \mathrm{~cm}$ ), and the notochordal canal is broadly open. The large Stenopterygius sample also contains evidence of prepartum embryo voiding from dead or dying adults (Böttcher, 1990). We therefore infer that the present specimen is a voided embryo rather than a neonate.

The occurrence of the embryo in a plesiosaur gut is somewhat puzzling. This is certainly the first record of the consumption of ichthyosaurs by plesiosaurs, but this is misleading if the ichthyosaur is a voided embryo. A wide variety of food items have been documented as gut contents in plesiosaurs, including cephalopod hooklets from true pliosaurs (Martill, 1992; Wahl et al., 2007), and fish fragments (Cicimurri and Everhart, 2001) and whole bivalves (McHenry et al., 2005) from elasmosaurs. It appears that carrion should be added to this list. 

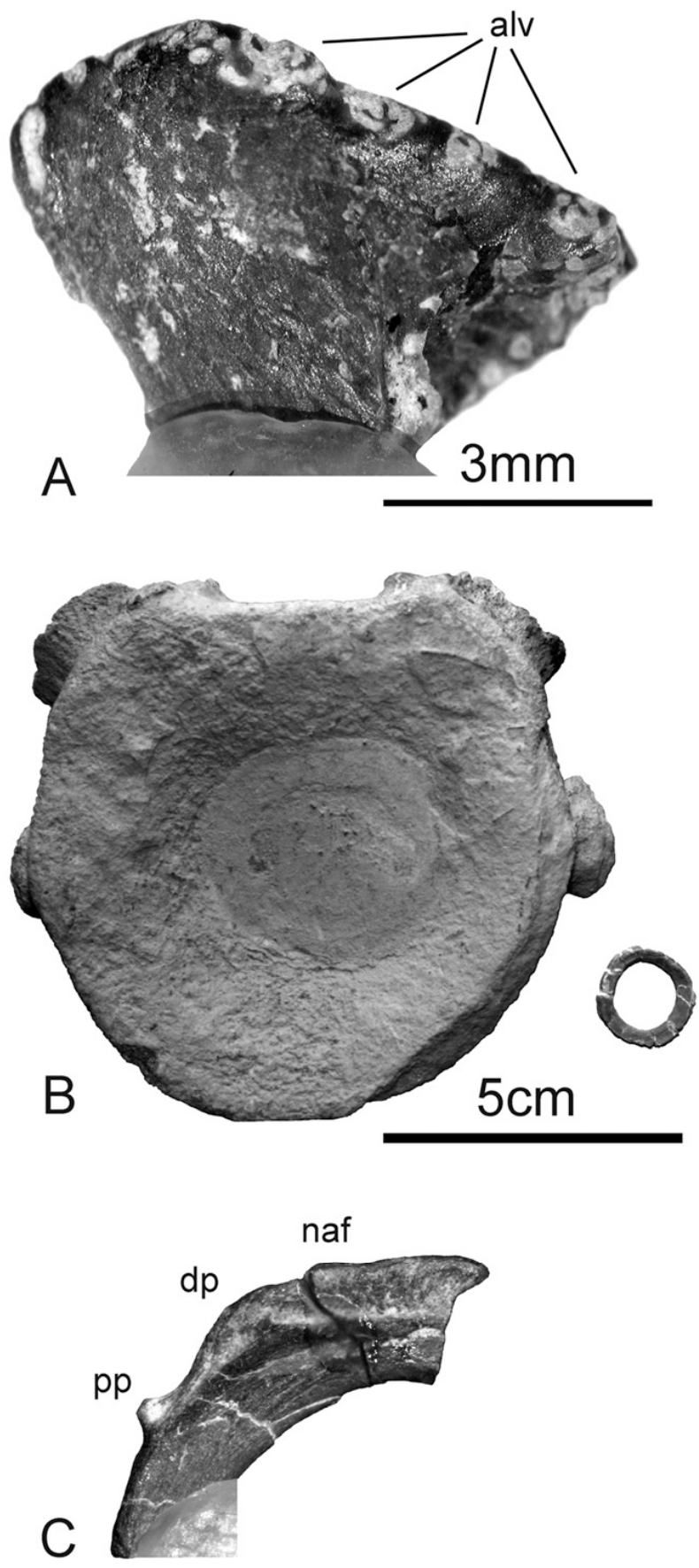

FIGURE 2. A, Tooth-bearing element recovered from the plesiosaur gastric mass. The teeth are very poorly developed but display infolded enamel, which is diagnostic for Ichthyosauria among marine reptiles. Identity of the element (maxilla or dentary), and displayed side (labial or lingual) are not known. B, Size comparison between an adult cervical vertebra of Opthalmosaurus natans (USNM 536972) and a completely prepared embryonic vertebral centrum recovered from the plesiosaur gastric mass. The center of the adult centrum is obscured by a small matrix concre-tion, but lacks an open notochordal canal, as is typical for adult ichthyosaurs. C, Detail of an embryonic centrum with relatively well-developed articula-tions for the rib and neural arch. This centrum is probably a cervical based on the dorsal location of the diapophysis and parapophysis. Abbreviations: alv, alveoli; dp, diapophysis; naf, neural arch facet; pp, parapophysis. 


\section{ACKNOWLEDGMENTS}

Special thanks are due to Cliff and Row Manuel, who first pointed out the potential of the field area that yielded this fossil, and for hospitality and assistance with the field program over several seasons. We thank E. Kvale, J. Marcot, K. Sears, S. Peters, and E. Love for assistance in the field. D. Hansen provided timely advice and permits from the Wyoming BLM, and we thank M. Carrano and the staff at the Smithsonian Institution for transport, curation, and other assistance. Comments by R. Holmes, E. Maxwell, and an anonymous reviewer greatly improved the manuscript, particularly Maxwell's comments on dental morphology and ontogeny. The Sundance Plesiosaur Project has been funded by National Geographic Society Committee for Research and Exploration Grant 7627-04, as well as New York College of Osteopathic Medicine research funds, and startup funds from the Marshall University Foundation.

\section{LITERATURE CITED}

Andrews, C. W. 1910. A Descriptive Catalogue of the Marine Reptiles of the Oxford Clay, Part I. British Museum (Natural History), London, 205 pp.

Andrews, C. W. 1913. A Descriptive Catalogue of the Marine Reptiles of the Oxford Clay, Part II. British Museum (Natural History), London, 206 pp.

Brown, D. S. 1981. The English Upper Jurassic Plesiosauridea (Reptilia) and a review of the phylogeny and classification of the Plesiosauria.

Bulletin of the British Museum of Natural History 35:253-347.

Böttcher, R. 1990. Neue Erkenntnisse über die Fortpflanzungsbiologie der Ichthyosaurier (Reptilia). Stuttgarter Beiträge zur Naturkunde (B) 164, Stuttgart 51.

Cicimurri, D. J., and M. J. Everhart. 2001. An elasmosaur with stomach contents and gastroliths from the Pierre Shale (Late Cretaceous) of Kansas. Transactions of the Kansas Academy of Science 104:129-143.

Gilmore, C. W. 1906. Notes on osteology of Baptanodon, with description of a new species. Memoirs of the Carnegie Museum 2:325-342.

Knight, W. C. 1898. Some new Jurassic vertebrates from Wyoming. American Journal of Science, Fourth Series 5(whole number 155):378-380.

Kvale, E. P., G. D. Johnson, D. L. Mickelson, K. Keller, L. C. Furer, and A.W. Archer. 2001. Middle Jurassic (Bajocian and Bathonian) dinosaur megatracksites, Bighorn Basin, Wyoming, U.S.A. Palaios 16:233-254.

Marsh, O. C. 1891. Geological horizons as determined by vertebrate fossils. American Journal of Science 42:336-338.

Marsh, O. C. 1893. Congress Geologique International, Compte Rendu de la 5me Session. Washington, D. C. 1891: 156-159.

Marsh, O. C. 1895. The Reptilia of the Baptanodon beds. American Journal of Science 50:405406.

Martill, D. M. 1992. Pliosaur stomach contents from the Oxford Clay. Mercian Geologist 13:3742.

Massare, J. A., and H. A. Young. 2004. Gastric contents of an ichthyosaur from the Sundance Formation (Jurassic) of central Wyoming. Paludicola 5(2):21-27.

Massare, J. A., E. A. Buchholtz, J. M. Kenney, and A. M. Chomat. 2006. Vertebral morphology of Ophthalmosaurus natans (Reptilia: Ichthyosauria) from the Jurassic Sundance 
Formation of Wyoming. Paludicola 5(4):242-254.

Maxwell, E. E., and M. W. Caldwell. 2003. First record of live birth in Cretaceous ichthyosaurs: closing an 80 million year gap. Proceedings of the Royal Society of London B (suppl.) 270:S104-S107.

Maxwell, E. E., and M. W. Caldwell. 2005. A new genus of ichthyosaur from the Lower Cretaceous of western Canada. Palaeontology 49:1043-1052.

Mazin, J. 1983. L’implantation dentaire chez les Ichthyopterygia (Reptilia). Neues Jahrbuch für Geologie und Pala"ontologie, Monatshefte 7:406-418.

McHenry, C. R., A. G. Cook, and S. Wroe. 2005. Bottom-feeding plesiosaurs. Science 310:75. Mehl, M. G. 1912. Muraenosaurus? reedii, sp. nov. and Tricleidus? Laramiensis Knight, American Jurassic plesiosaurs. Journal of Geology 20:344-352.

O’Keefe, F. R., and H. P. Street. 2009. Osteology of the cryptocleidoid plesiosaur Tatenectes laramiensis from theUpper Sundance Formation of the Bighorn Basin, Wyoming. Journal of Vertebrate Paleontology 29:XXX-XXX.

O’Keefe, F. R., and W. Wahl. 2003a. Current taxonomic status of Pantosaurus striatus from the Upper Jurassic Sundance Formation. Wyoming. Paludicola 4:37-47.

O’Keefe, F. R., and W. Wahl. 2003b. Preliminary report on the osteology and relationships of a new aberrant cryptocleidoid plesiosaur from the Sundance Formation. Wyoming. Paludicola 4:48-68.

Rieppel, O. 1992. Studies on skeleton formation in reptiles. III. Patterns of ossification in the skeleton of Lacerta vivipara Jacquin (Reptilia, Squamata). Fieldiana (Zoology) New Series 68:1-25.

Sato, T., and X.-C. Wu. 2006. Review of plesiosaurians (Reptilia: Sauropterygia) from the Upper Cretaceous Horseshoe Canyon Formation in Alberta, Canada. Paludicola 5:150-169.

Thompson, W. A., J. E.Martin, M. Reguero, 2007. Comparison of gastroliths within plesiosaurs (Elasmosauridae) from the Late Cretaceous marine deposits of Vega Island, Antarctic Peninsula, and the Missouri river area, South Dakota; pp. 147-153 in J. E. Martin and D. C. Parris (eds.), The Geology and Paleontology of the Late Cretaceous Marine Deposits of the Dakotas. Special Paper 427, Geological Society of America.

Wahl, W. R. 2006. A juvenile plesiosaur (Reptilia: Sauropterygia) assemblage from the Sundance Formation (Jurassic), Natrona County, Wyoming. Paludicola 5:255-261.

Wahl, W. R., M. Ross, and J. A. Massare. 2007. Rediscovery of Wilbur Knight’s Megalneusaurus rex site: new material from an old pit. Paludicola 6:94-104.

Wings, O. 2007. A review of gastrolith function with implications for fossil vertebrates and a revised classification. Acta Palaeontologica Polonica 52:1-16.

Zaher, H., and O. Rieppel. 1999. Tooth implantation and replacement in squamates, with special reference to mosasaur lizards and snakes. American Museum Novitates 3271:1-19. 